\title{
XXXIII. The diurnal variation of atmospheric electrical quantities
}

\section{E.H. Nichols B.Sc. A.R.C.Sc.}

To cite this article: E.H. Nichols B.Sc. A.R.C.Sc. (1916) XXXIII. The diurnal variation of atmospheric electrical quantities, Philosophical Magazine Series 6, 32:189, 282-294, DOI: $10.1080 / 14786441608635573$

To link to this article: http://dx.doi.org/10.1080/14786441608635573

曲 Published online: 08 Apr 2009.

Submit your article to this journal

Џlll Article views: 3

Q View related articles $₫$ 
remarkable that the law of equipartition of energy of the kinetic theory of gases gives an angular velocity of the same order. In fact, taking for the mean translational velocity of iodine molecules at $0^{\circ} \mathrm{C}$. the value $1 \cdot 64.10^{4} \mathrm{~cm}$./sec. and for the molecular radius $2 \cdot 10^{-8} \mathrm{~cm}$, and attributing to the molecules two exchangeable rotational momentoids, against three translational ones, I find for the average angular velocity

$$
\bar{\omega}=1 \cdot 59.10^{12} \text {, }
$$

which is well comparable with the above value.

I gladly take the opportunity of expressing my thanks to Professor R. W. Wood, who has drawn my attention to these beautiful phenomena and has encouraged me to take up the subject of resonance-spectra from the theoretical standpoint.

July $27,1916$.

XXXIII. The Dinrnal Variation of Atmospheric Electrical Quantities. By E. H. Nichors, B.Sc., A.R.C.Sc. ${ }^{*}$

TTHE diurnal variation of the electrical conductivity has 1 been investigated recently by Kahler $\uparrow$ and Dorno $\ddagger$ by means of a continuously recording dissipation apparatus, while Gockel § has obtained eye observations of conductivity and electric charge. For the investigations here detailed, two Ebert Electrometers $\|$ have been used to record the respective positive and negative electric charges, while the Wilson Compensating Gold Leaf Electroscope 9 measured the conductivity and air-earth current, tho potential being obtained from a Kelvin Water-Dropper apparatus. The method employed for the Wilson instrument was a variation of the original method adopted by C. T. R. Wilson. There are three operations involved :-

(a) The charge on the test-plate is first found by removing the cap, and replacing it quickly after momentarily earthing

* Communicated by the Director of the Meteorological Office.

† Ergebnisse der Met. Beob. im Potsdam, 1909, 1911.

₹ "Studie über Licht und Luft des Hochgebirges," 1911 (Davos).

\$ Mache u. von Schweidler, Atmosphärische Elektrizität, 1909, p. 90; A. Gockel, Met. Zeit. xxiii. pp. 53, 339 (1906); xxv. p. 9 (1908); Archives des Sc. phys. et nat., Sept. 1913.

II Phys. Zeit. viii. 8. p. 246; viii. 16. p. 527; x. 8. p. 251.

Tी Proc. Camb. Phil. Soc. xiii. p. 184 (1906). M. O. Geophys. Mem. No. 7. 
Variation of Atmospheric Electrical Quantities. 283 the plate. The reading of the gold leaf is taken $\left(g_{1}\right)$, and also after again earthing $\left(g_{0}\right)$. During this operation the compensator must be fully out. The charge on the plate is represented by $\left(g_{1}-g_{0}\right)$.

(b) The charge lost in five minutes from the test-plate is obtained by removing the cap and adjusting the compensator until the reading of the gold leaf is again $g_{0}$, and remains at $g_{0}$ for the five-minute period. The cap is then replaced and the compensator fully drawn out. The gold leaf is again read $\left(g_{2}\right)$ and also after earthing $\left(g_{0}^{\prime}\right)$. The leakage in the test-plate due to the air-earth current is represented by $\left(g_{2}-g_{0}^{\prime}\right)$.

(c) The first operation $(a)$ is repeated to find the charge on the plate $\left(g_{3}-g_{0}{ }^{\prime \prime}\right)$.

The conductivity is given by

$$
\lambda=5 \cdot 89\left\{\left(g_{2}-g_{0}{ }^{\prime}\right) /\left(g_{1}+g_{3}-g_{0}-g_{0}{ }^{\prime \prime}\right)\right\} \times 10^{-25} \text { e.m.u., }
$$

where 5.89 is a universal constant, and no instrumental calibration is involved *. The formula may be proved as follows. The surface density of the charge on the testplate is given by

$$
\sigma=\text { electric force } / 4 \pi=\frac{1}{1200 \pi} \text { e.s.u. }
$$

for a potential gradient of 100 volts per metre (1 volt per cm.). Supposing the loss of charge on the test-plate is $p$ per cent. per minute, then the current is equal to

$\frac{1}{1200 \pi} \times \frac{p}{100} \times \frac{1}{60}$ e.s.u. per second $=1 \cdot 473 p \times 10^{-17} \mathrm{amp} . / \mathrm{sec}$.

For a potential of $v$ volts per cm., the current

$$
=1.473 p v \times 10^{-17} \mathrm{amp} . / \mathrm{cm}^{2}
$$

The percentage loss per minute (for five-minute intervals)

$$
\begin{aligned}
& =p=100\left(g_{2}-g_{0}{ }^{\prime}\right) /\left[5 \times \frac{1}{2}\left(g_{1}+g_{3}-g_{0}-g_{0}{ }^{\prime \prime}\right)\right] \\
& =40\left(g_{2}-g_{0}{ }^{\prime}\right) /\left(g_{1}+g_{3}-g_{0}-g_{0}{ }^{\prime \prime}\right) .
\end{aligned}
$$

* This assumes the constancy in scale value for the divisions in the eyepiece. 
Therefore the current

$$
=5 \cdot 89 v\left\{\left(g_{2}-g_{0}{ }^{\prime}\right) /\left(g_{1}+g_{3}-g_{0}-g_{0}{ }^{\prime \prime}\right)\right\} \times 10^{-16} \text { amp./cm. }{ }^{2} \text {, }
$$

and the conductivity

$$
=5.89\left\{\left(g_{2}-g_{0}^{\prime}\right) /\left(g_{1}+g_{3}-g_{0}-g_{0}^{\prime \prime}\right)\right\} \times 10^{-25} \text { e.m.u. }
$$

The mobility, or the ionic velocity under the influence of unit gradient of 1 volt per cm., can be calculated from the conductivity $(\lambda)$ and the positive charge $\left(\mathrm{E}_{+}\right)$. It is considered that the conductivity measured by the Wilson electrometer is that due to the positive ions*, so that $\lambda_{+}=E_{+} \mu_{+}$, where $\mu_{+}$is the mobility of the positive ions.

Observations of the diurnal variation of the electrical elements were commenced at Kew Observatory in May 1914, and continued during June and July on four days of each month (Table I.), with an additional day in August (Table III.). During May and June hourly observations were taken, from 7 A.M. to 8 P.M., each extending for about 15 minutes, while during July and August the times were from 4 A.M. to 8 P.M. The weather conditions were exceptionally favourable, only a very few days being affected by rain. As the instruments must be suitably mounted in the open, any rain beyond a slight drizzle prevents continued observation. Synchronous values of the potential were obtained from the Kelvin water-dropper, a factor being applied to convert the values to the potential gradient in the open.

A few hourly results are missing for the different elements. In these cases the mean value for the preceding and following hour has been used, while in one or two instances hourly values have been extrapolated by the usual method.

The mean summer diurnal variation for Kew obtained from twelve days in May, June, and July is shown in fig. 1 . There is a maximum for the positive charge at 11 A.n. and for the conductivity at 2 P.M. The air-earth current shows no important variation, but the mobility gives a decided increase after noon. The potential curve indicates a definite minimum in the afternoon, and agrees closely with the normal for 1898$1912 \dagger$ for those months, thus proving that the variation of the elements obtained should be generally applicable to electrically quiet days.

* Lutz, Luftelektrische Messungen am München, 1911.

† C. Chree, Phil. Trans. A.ccxv. p. 141. 
Variation of Atmospheric Electrical Quantities.

Fig. 1.-Kew, 1914.

Nean Diurnal Variation (May, June, July) (unsmoothed).

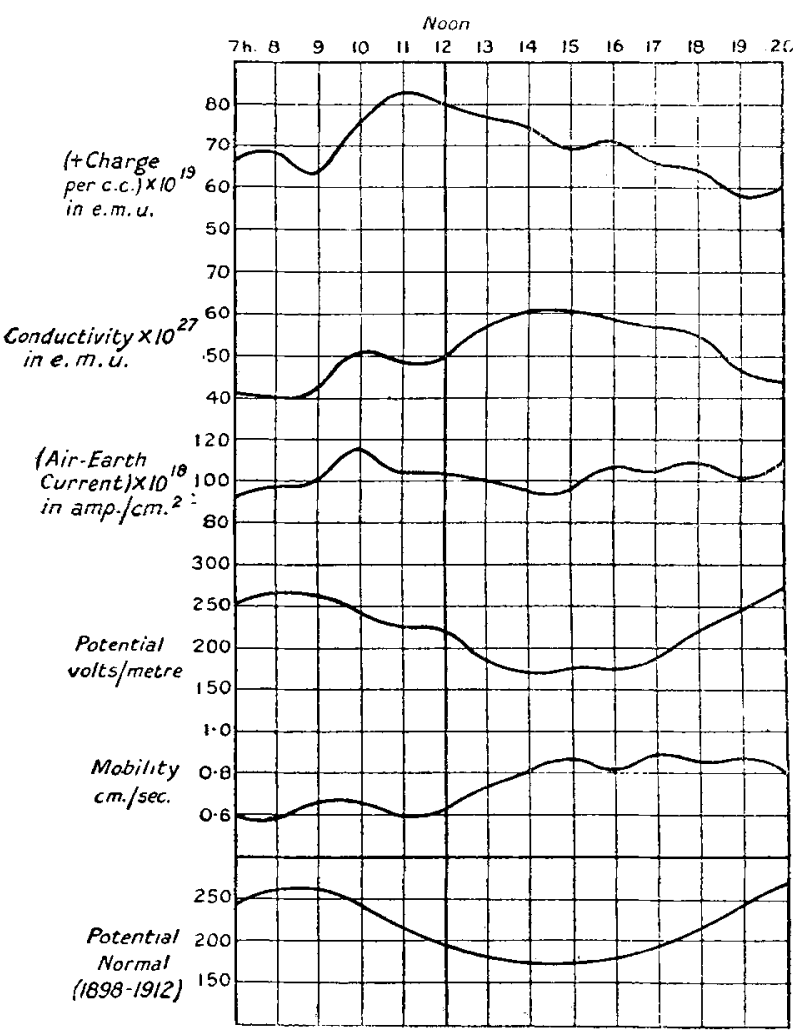

Monthly Means for May, June, and July, 1914.

From the results for May given in Table I., there is a minimum for the positive charge at 9 A.M. and two almost equal maxima at 11 A.M. and 2 P.M., while the conductivity shows a well-marked minimum at 8 A.M. and maximum at 4 P.M. The air-earth current shows a minimum at 8 A.M., which corresponds with a maximum of potential. The potential is low during the afternoon with a minimum at 1 P.M., while the mobility increases gradually during the day. For June the positive charge has a maximum value at noon, and two minima at 9 A.M. and 7 P.M., which correspond with the times for minima in the conductivity. As usual, the maximum for the positive charge precedes that for conductivity by a few hours. The air-earth current varies somewhat similarly to the potential, and the mobility increases during the day to a maximum at 5 P.M. 
The results for July give a more detailed account of the electrical conditions, as the negative charge was also measured and observations commenced three hours earlier. The range for the conductivity is considerably less than for the other months, there being a maximum at 1 P.M. and a minimum during the night. There is a curious well-marked minimum at 11 A.M. which corresponds to a maximum electric charge. Individual results show a minimum at 11 A.M. for July 23, 28, and 30, while for July 21 there is one at 9 A.M. The minimum at $11 \mathrm{~h}$. appears in the 3-monthly means, and the depression from 10 A.M. to 1 P.M. is more pronounced still in the Eskdalemuir results discussed below, so that it is probably a real phenomenon.

Although the data for the individual days cannot be discussed in detail, a few points may be noticed. There appears to be no definite effect of precipitation on the electrical quantities as a general rule, but there are cases in which a considerable decrease in electric charge or conductivity has been observed to follow rain (see Table III.). In the fow measurements made before and after thunderstorms, the electrical values obtained show nothing abnormal. Usually there is a similarity between the variation of the conductivity and the positive and negative charges, the two latter showing a close agreement. There is also a definite minimum about midday in the ratio of the positive and negative charges $\left(\frac{\mathrm{E}_{+}}{\mathrm{E}_{-}}\right)$, which is obviously associated with
the solar effect.

A partially successful attempt was made on June 29-30, 1914, to obtain the electrical variation for the complete 24 hours, observations being commenced at 7 A.M. on June 29 and continued hourly till 7 A.M. June 30 (see Table II.). After 9 P.M., however, the Wilson electroscope failed owing to insulation trouble, which is a great difficulty in night work. For such work an electric torch must be used for reading, oil lamps being fatal to results, because of the production of conducting gases. The diurnal variation of electric charge gave some indication of a double period with primary maximum and minimum about 4 P.M. and 4 A.M. respoctively. The values for both charges were lower at night than during the day. The ratio of the charges $\left(\begin{array}{l}\mathrm{E}_{+} \\ \mathrm{E}_{-}\end{array}\right)$shows a remarkable maximum at 3 A.M. and a minimum at 12 noon. Such an outstanding maximum might appear fortuitous, but similar examples of high maxima occurred on July 23 at 4 A.M., July 28 at 5 A.M., and August 4 at 5 A.M. 
Variation of Atmospheric Electrical Quantities. $\quad 287$

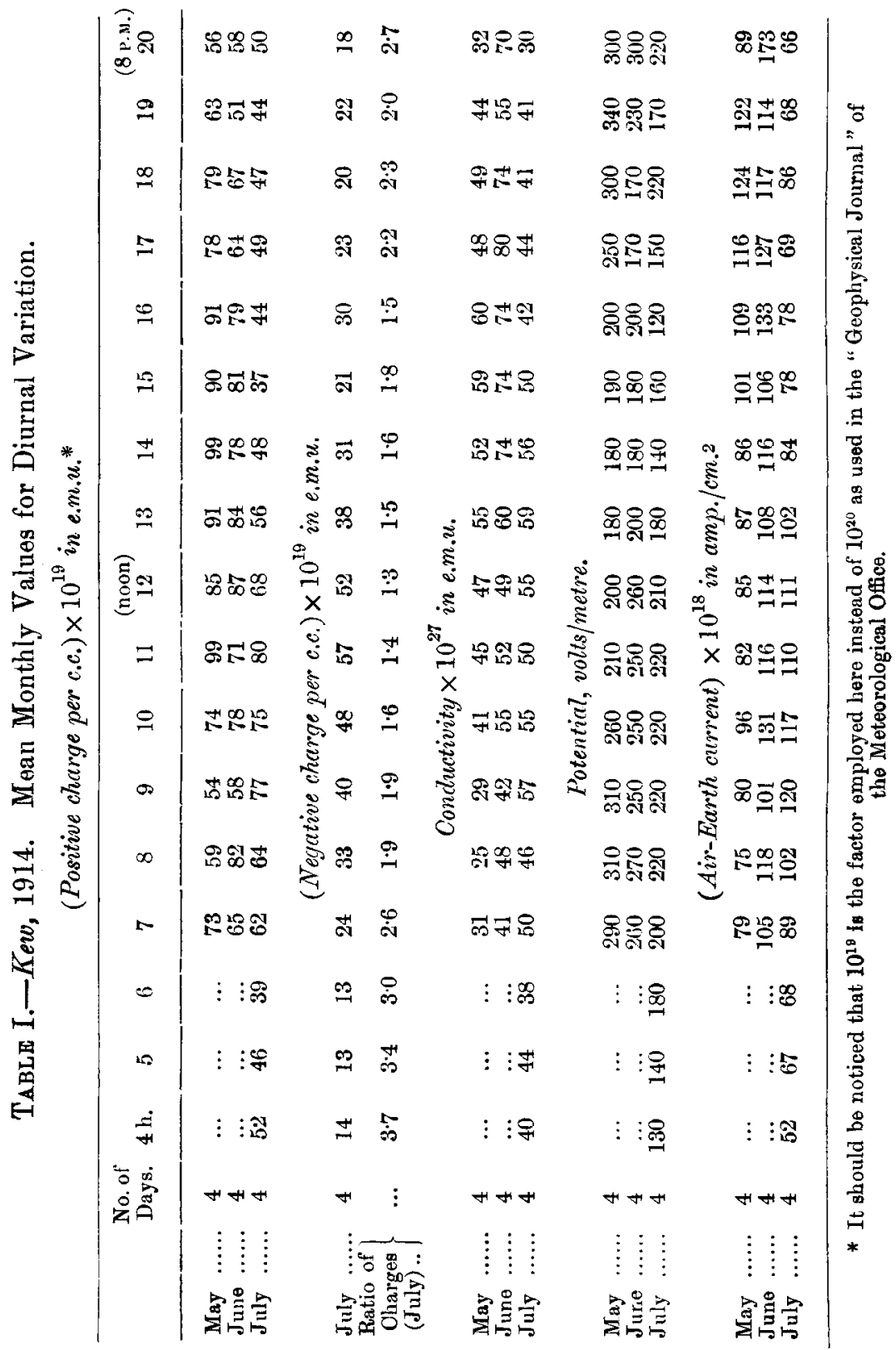




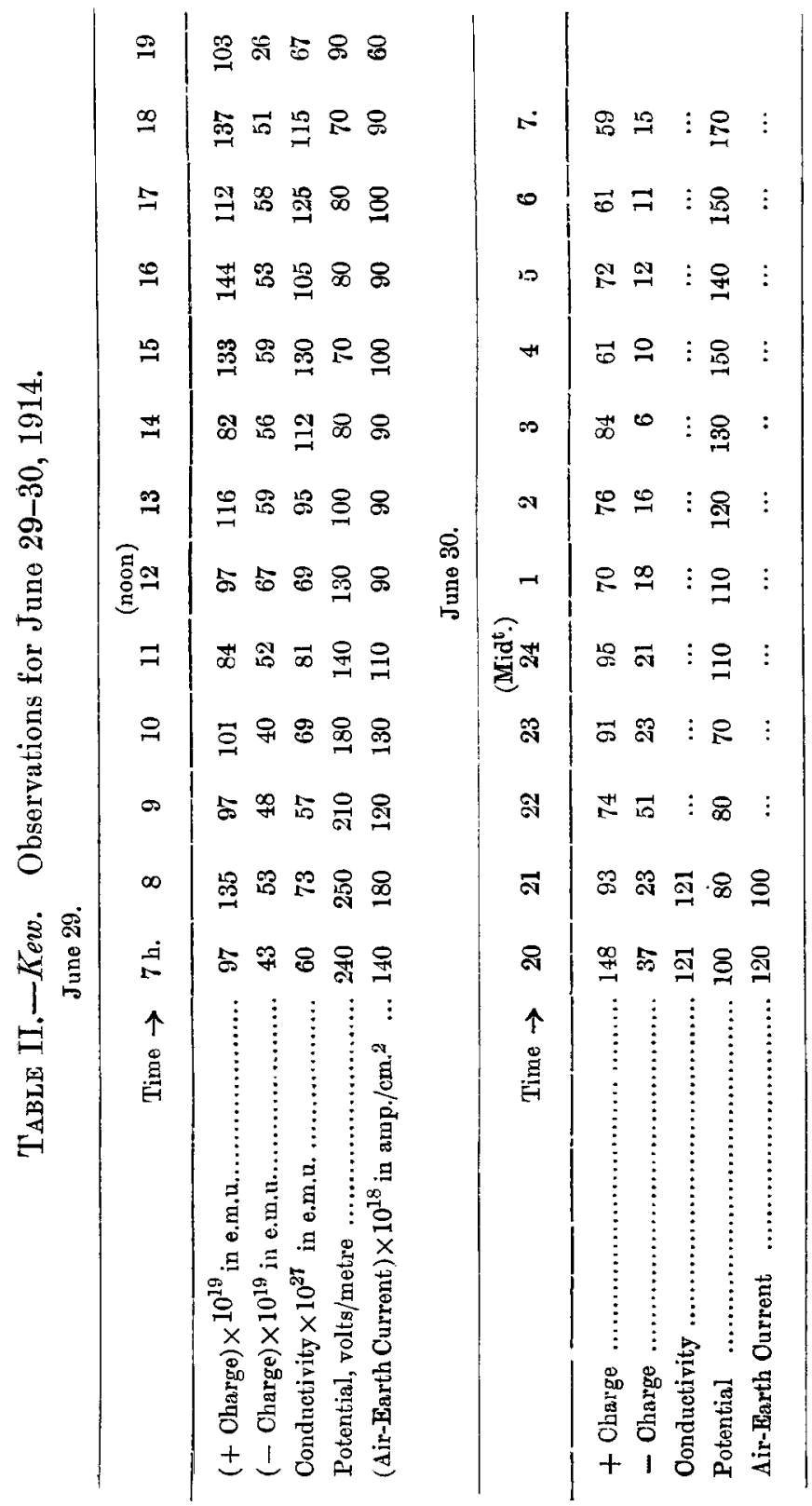


Variation of Atmospheric Electrical Quantities. $\quad 289$

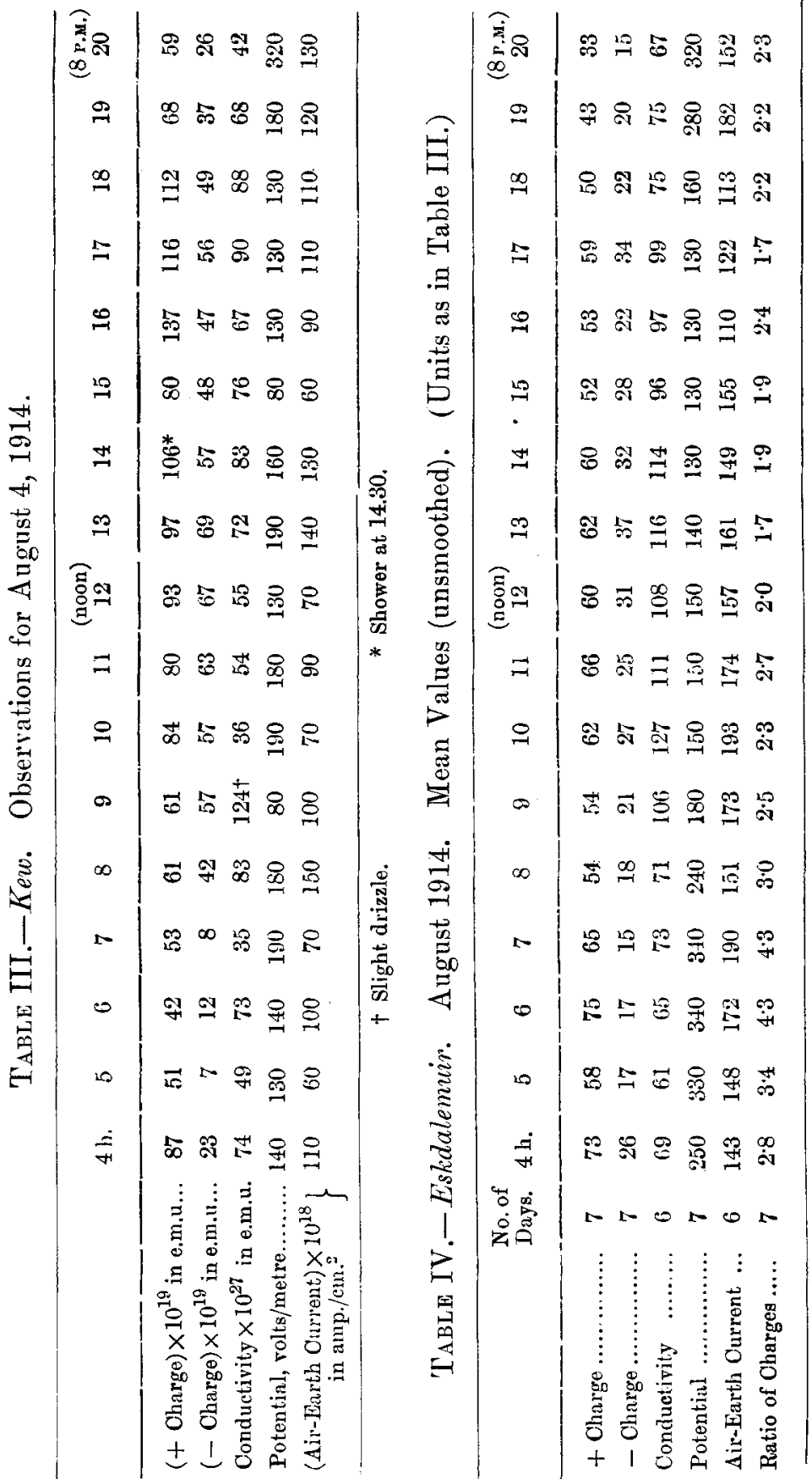


Observations at Eskdalernuir during August 1914.

As Kew Observatory is only a few miles from London and practically at sea-level, it will be advantageous to compare the electrical variation with that for Eskdalemuir (237 metres above M.S.L.) in Dumfriesshire, removed from disturbing artificial conditions. The importance of the electrical investigation was increased by the fact that it was possible to include a day of partial solar eclipse, and thus compare the diurnal variation obtained with that for the normal day. Observations of the conductivity variation were made on six days, and of the electric charges on seven days, viz. August 13, 14, 17, 20, 22, 28, and 31. As the eclipse day was August 21, it was considered important for comparison to observe on the preceding and following day, and also to bave the other days well balanced with respect to August 21.

Comparing the monthly means at Kew and Eskdalemuir, the conductivity is vearly twice as great at the latter place (see Tables I. and IV.). There is a corresponding early morning minimum about 5 A.M. for both places, and the July depression at Kew about midday is repeated for August at Eskdalemuir. The most remarkable difference in the variation is the sharp increase in conductivity at Eskdalemuir between 8 and 10 A.M., there being only a small rise at Kew. This is certainly to be associated with the rapid disappearance at Eskdalemuir of the morning mist, which was frequently dissipated during these hours. Because of the decreased relative humidity the charged ions in the air would lose a percentage of their water molecules, thus increasing their mobility and, consequently, the conductivity of the air.

It is noticeable that the charges at Eskdalemuir varied less than at Kew. The mean positive charge is about $6 \times 10^{-18}$ e.m.u. at both places. For the electric charges at Eskdalemuir there is a maximum about noon, and a minimum during the night. There is also an indication of a secondary maximum and minimum in the early morning. The ratio of the charges $\left(\frac{\mathrm{E}_{ \pm}}{\mathrm{E}_{-}}\right)$shows a decrease during the day with a minimum at 1 P.M., which agrees well with the Kew results. The air-earth current is somewhat irregular, and there is no well-marked variation. It should be noted that the conductivity and potential were both high at Eskdalemuir, so that the air-earth current is high, while the mobility shows 100 per cent. increase from 4 to 10 A.M. and maintains an almost steady value for the rest of the day, being about double that obtained at Kew. 
Eclipse Observations, August 21, 1914.

Instrumental readings were taken every hour from 4 A.M. to 10 A.M., and then every half-hour to 8 P.M. The duration of the eclipse was from 10 A.M. to 1 P.M., with a maximum phase of 0.7 for Eskdalemuir. The meteorological conditions were not ideal, as in the early morning there was a wet mist, which made observation very difficult. About 8-9 A.M. the air became drier, but it was still dull, the sun being only visible for short periods, and then dimly through thin Stratus and Strato-Cumulus. At 2 P.M. and 2.40 P.M. a little rain fell, but not sufficient to prevent observation. The diurnal variation observed is quite different from that obtained on ordinary days. In order to compare the results more conveniently, they have been represented graphically in figs. 2 and 3.

Fig. 2.-Eskdalemuir, 1914.

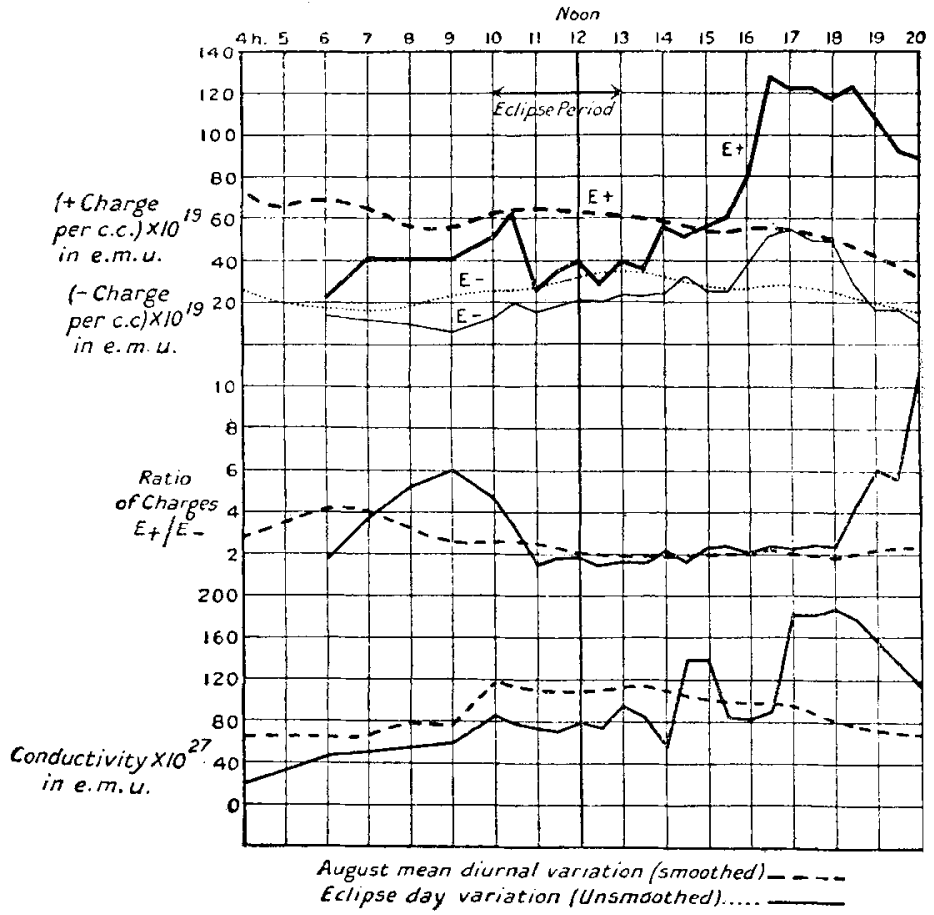

As the normal variation for August is only obtained from 6 or 7 days, it appeared desirable to smooth the values given in Table IV. by means of the formula $\frac{a+2 b+c}{4}$. The 
eclipse day variation is, however, unsmoothed. There is a considerable decrease in conductivity and electric charges from 10 A.M. to 5 P.M., commencing soon after the primary phase of the eclipse. The maximum for the day, instead of appearing in the early afternoon, is retarded till about 5 P.M. There is a decrease in the mobility which might be explained by the fact that increased relative humidity due to the fall in temperature during the eclipse causes condensation of

Fig. 3.-Eskdalemuir, 1914 (continued).

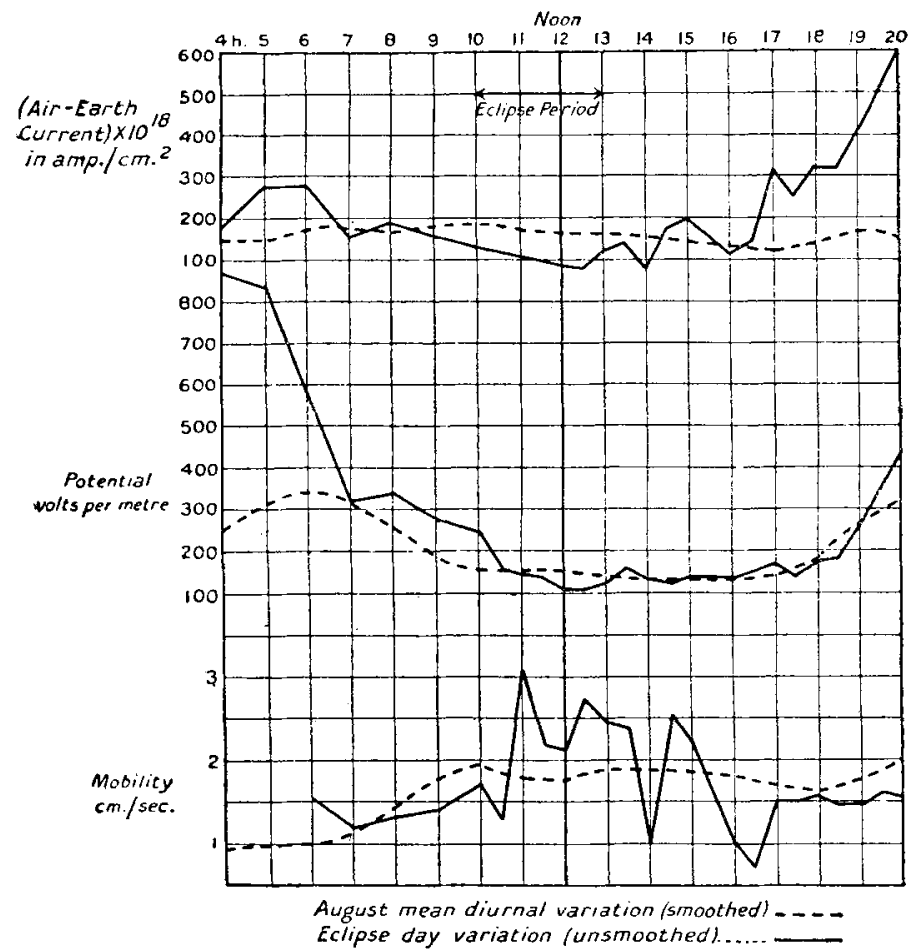

water molecules on the ions. There is but little indication of an increase in the ratio of the electric charges, which has been found by some observers, during or near the totality stinge, and ascribed to the reduction in the number of the negative ions*.

Superficial observation might connect the depression in the electrical quantities from 10 A.M. to 1 P.M. with the eclipse, but a similar depression is obtained in the August

* Leyst, Luftelektrischen Beobachtungen, 1907. 
mean, and is more or less distinctly apparent in the individual days except August 31. Thus it seems to indicate a general phenomenon. It was often noticed at Eskdalemuir during this month that an early morning ground-mist was dissipated between 8 and 10 A.M. and was followed by bright sunshine with cloudless sky lasting a short time but becoming overclouded towards noon. Although at 10 A.M. the mist had quite cleared on the slopes near the Observatory, it was often visible in the valleys. It is possible that the dissipation of the valley-mist to higher levels might cause a decrease in the mobility of the ions, and so in the conductivity.

In order to study the eclipse effect more closely, the results for August 20 and 22 may be considered. The general form of the variation for both days was similar except that on August 22 the increase in the conductivity and the electric charges from 7 to 10 A.M. was very marked, and also that instead of a gradual fall from 4 to 8 P.M. there was an increase, this being especially marked in conductivity. The mean for the two days shows a deeper depression in conductivity between 10 A.M. and 1 P.M. than is obtained on August 21. This reduces the probability that any eclipse factors produced the diminution of electrical quantities on the day of eclipse between these hours. But when we consider the retarded maximum in the conductivity and both charges, there is some justification for considering it to be the result of an indirect solar effect. Some observers have considered it sufficient in eclipse work only to investigate the electrical variation during the actual phases, but a lag in producing any electrical effect would make later hours important. Wiechert's reasoning * with respect to solar radiation and the maintenance of atmospheric ionization, indicate the probability of a lag in any eclipse effect which may be due to the suspension of the ionizing influence of ultra-violet light. Although most eclipse observers in the past do not appear to have noticed any striking electrical changes, it is to be hoped that a longer series of observations will be possible in the future at stations situated near the line of totality, with sufficient observations on preceding and following days to obtain the normal form of the diurnal variation.

The few results obtained by G. Dobson + and other observers $\ddagger$ show generally a diminution of conductivity and

* "Les Recherches sur l'Electricité Atmosphériyue," Arch. des Sc. Phys. et Nat. 1912, p. 385.

$\dagger$ Q. J. Roy. Met. Soc. 1913, p. 221.

$\ddagger$ Ludeling \& Nippoldt, Abhand. d. Kon. Preuss. Met. Inst. 1908. 


\section{Diurnal Variation of Atmospheric Electrical Quantities.}

number of ions per c.c. during the eclipse period. For the 1912 eclipse at Kew the conductivity and number of ions showed a decided increase during the first phase, but this was followed by a well-marked depression. For Eskdalemuir, no marked change in potential was found, and this agrees with the results from other eclipses.

It is well to emphasize that while small instrumental differences may have existed between the three Ebert electrometers used, as we were at that time dependent on values supplied for the capacity and anemometer readings by the makers, these uncertainties cannot affect the character of the diurnal variation described above, because for any one element only one instrument is involved.

There is some difference of opinion as to the best method of treatment of results from the Wilson electroscope. Some experiments of G. Dobson * at Kew appear to show that the conductivity as measured usually with the Wilson instrument on a tripod-stand 1.3 metres from the ground is smaller than that measured at ground-level, owing to the crowding together of the equipotential surfaces above the test-plate and the production of a saturation current. The correction for the conductivity to bring it to ground-level values was +20 per cent. The mean for these corrected values is similar to the total conductivity rocorded by the Ebert instrument. As the individual results differed so widely, and owing to the insensitiveness of the Ebert apparatus many negative values for mobility and conductivity were obtained with it, the deduction is not convineing that the corrected conductivity obtained from the Wilson apparatus corresponds with the total conductivity measured by the Ebert apparatus. Under existing conditions, it has been thought advisable to continue the old mode of reduction until a more satisfactory method is devised. The results detailed above are, however, quite comparable, as the observational conditions were uniform.

In conclusion, I desire to acknowledge my indebtedness to several members of the Observatory staff at $\mathrm{Kew}$ and Eskdalemuir for assistance in carrying out the experimental work involved, especially to Dr. C. Chree, F.R.S., Superintendent of Kew Observatory, under whose supervision the work has been carried out, and also to Lieutenant C. D. Stewart, who performed a number of the earlier observations. 